\title{
A percepção dos riscos da atividade fumageira e sua contribuição na busca da reconversão produtiva no Assentamento de Reforma Agrária 25 de Maio, Santa Terezinha - SC
}

\section{The Risk Perception of Tobacco Production and its Contribution in the Productive Conversion Discussion in the Settlement 25 de Maio, Santa Terezinha/SC - Brazil}

\author{
Fernanda Savicki de ALMEIDA* \\ Luis Alejandro Gutierrez LASSO** \\ Clarilton Edzard Davoine Cardoso RIBAS ${ }^{* * *}$
}

\begin{abstract}
RESUMO
Organizações internacionais reportam que a produção mundial de fumo tem declinado ao longo dos últimos quinze anos entre os principais países produtores. Entretanto, o Brasil apresentou um incremento significativo de sua produção na última década, consolidando-se no segundo lugar como produtor mundial desde 2000. Por outro lado, percebe-se um aumento da mobilização e tomada de medidas em relação aos riscos decorrentes do consumo de tabaco em nível mundial; porém, aos riscos associados à produção a intensidade tem sido menor. Considerando que a percepção de risco é uma construção social ancorada na dimensão sociocultural e no efeito concreto produto de uma ação, o presente documento discute a percepção dos agricultores do Assentamento 25 de Maio sobre os riscos decorrentes da produção fumageira e examina a contribuição que esta reflexão coletiva sobre a percepção dos riscos aporta a um processo de reconversão produtiva por plantas medicinais, aromáticas e condimentares. Destaca-se que todas as famílias entrevistadas deixariam de produzir fumo, já que percebem esta atividade como a causa da deterioração de suas condições de trabalho e de saúde. Contudo, o retorno econômico que aparentemente a atividade gera é o fator que determina sua maior sensibilidade a esse tipo de risco. Todavia, a singularidade da pertença dessas famílias a um movimento social fortalece a percepção coletiva e reflexiva dos riscos da atividade fumageira e contribui como base para um processo de reconversão produtiva.
\end{abstract}

Palavras-chave: percepção de risco; produção de fumo; assentamentos de reforma agrária; reconversão produtiva.

\footnotetext{
"Msc. Agroecossistemas. Universidade Federal de Santa Catarina - UFSC. Pesquisadora do Laboratório Educação do Campo e Estudos da Reforma Agrária - LECERA/UFSC. Email: fernanda_savicki@hotmail.com

"* Doutorando PG Interdisciplinar em Ciências Humanas - UFSC. Pesquisador do Núcleo de Meio Ambiente e Desenvolvimento - NMD/UFSC. Email: alejoscout98@gmail.com

*** Prof. Dr. PG Agroecossistemas - UFSC. Coordenador do Laboratório Educação do Campo e Estudos da Reforma Agrária - LECERA/UFSC. Email: ccribas17@ hotmail.com
} 


\begin{abstract}
International organizations report that over the last fifteen years tobacco production has declined among the world's principal producing countries. However, Brazil has shown a significant increase of their production in the last decade, consolidating itself as the second largest world producer since 2000. Furthermore, we find that the mobilization efforts and measures taken in relation to the risks of tobacco consumption worldwide have been increased, while those associated with the risks of tobacco production have not. Whereas the risk perception is a social construction rooted in the socio-cultural dimension, as well as in the concrete effect of an action, this paper discusses the perception of farmers from the settlement known as " 25 de Maio", with respect to the risks of tobacco production. It also examines the contribution that this reflection on the collective risk perception makes to a process of converting production to medicinal plants, herbs and condiments. It appears that all of the families interviewed would stop producing tobacco since they realize that this activity causes the deterioration of their working conditions and health, but the income generated is the factor that determines their decision to work in this activity. However, the fact that these families belong to a social movement strengthens the collective perception of and reflection on the risks inherent to tobacco production, and contributes as a foundation for the process of production conversion.
\end{abstract}

Key-words: risk perception; tobacco production; settlements; conversion production.

\section{Introdução}

Na década de 1970, teve início um crescente movimento que denunciava os efeitos negativos do tabaco. Suas demandas se consolidaram em junho de 2003, quando foi firmado, em Genebra, o Convênio Marco da Organização Mundial da Saúde (OMS) Para o Controle do Tabaco. Desde então, ações concretas contra o tabagismo têm aumentado no mundo.

A produção mundial de fumo tem declinado ao longo dos últimos quinze anos entre os principais países produtores e, segundo Carvalho (2006), essa queda foi de $13,2 \%$ na quantidade produzida. A Organização das Nações Unidas para Agricultura e Alimentação - FAO (2003) traz dados mais detalhados, mostrando que essa queda está relacionada somente aos países ditos desenvolvidos, tendo a produção diminuído de 2,3 milhões de toneladas em 1976 para 1,2 milhão de toneladas em 2000. Entretanto, nos países em desenvolvimento a produção, que era de 3,2 milhões toneladas em 1976, aumentou para 6 milhões em 2000.

O crescimento da produção brasileira foi de $26,4 \%$ entre os anos 1999 e 2008, sendo sua produção de 626.161 toneladas e 850.143 toneladas de folhas, respectivamente (IBGE, 2009). De acordo com os dados da Associação dos Fumicultores do Brasil (2009), esse montante de 2008 foi produzido por um total de 180.520 produtores brasileiros. $\mathrm{O}$ acréscimo na produção levou o Brasil ao posto de segundo maior produtor mundial já em 2000, como apresenta a FAO (2003), e primeiro lugar em exportações desde 1993 (CARVALHO, 2006; BACKES, 2008).

Dados associados aos riscos à saúde pelo consumo de tabaco são amplamente difundidos e podem ser acessados através de informações obtidas em organismos como a FAO, a OMS e o Ministério da Saúde. Frente a essa situação de risco, várias medidas têm sido tomadas, como, por exemplo, a proibição do consumo de tabaco em lugares públicos, implementada em um número cada dia maior de cidades no mundo.

A OMS reporta que o número de mortes pelo uso do tabaco é da ordem de 4,9 milhões anuais no mundo, o que corresponde a mais de 10 mil mortes por dia. No Brasil, estima-se que cerca de 200 mil mortes/ano são decorrentes do tabagismo. (MINISTÉRIO DA SAÚDE, 2009).

O tabaco é um fator de risco para seis das oito principais causas de morte no mundo, como doenças cardíacas e vasculares, pneumonias, câncer de pulmão, brônquios e traqueia (OMS, 2008). Atualmente, dos cerca de 1,1 bilhão de fumantes existentes no mundo $80 \%$ vivem em países em desenvolvimento (BANCO MUNDIAL, 1999).

No Brasil também se expressa essa tendência mostrada pelo Banco Mundial. O inquérito realizado pelo Instituto Nacional do Câncer (INCA) no ano de 2001 mostrou que, embora a prevalência de fumantes tenha diminuído quando comparada com o mesmo inquérito realizado em 1989, a 
proporção de fumantes entre a população de baixa renda e estudantes manteve-se maior que em grupos de maior renda e escolaridade (CAVALCANTI, 2006).

Por outro lado, informações relacionadas aos riscos ambientais, sociais e à saúde das pessoas envolvidas na produção do tabaco ainda são escassas. Adicionalmente, a pouca informação disponível e a forma de difusão não evidenciam o vínculo entre as características do sistema de produção e os riscos pelo consumo. Isso faz com que, no imaginário coletivo, não se reconheça que o conjunto de riscos decorrentes do fumo é mais complexo do que aquele associado somente à saúde do consumidor de tabaco.

Entretanto, há cerca de 20 anos atrás, aqui no Brasil, iniciou-se um movimento antifumo na forma de uma grande rede, unindo diversos movimentos sociais rurais e urbanos. Entre a pauta de reivindicações principais estava o questionamento ao sistema produtivo adotado, a contaminação ambiental pelo uso de agrotóxicos e a saúde dos agricultores e agricultoras envolvidos no processo produtivo (BOEIRA, 2000).

A região Sul é a maior produtora de fumo do Brasil, detendo 96,9\% da produção atual, sendo Santa Catarina o segundo Estado em produção, com 230.627 toneladas de folha, o que representou $27,1 \%$ da produção total do país no ano de 2008. A região Norte catarinense aportou 68.475 toneladas de fumo em folhas no ano de 2007 ao Estado de Santa Catarina (IBGE, 2009).

Essa região caracteriza-se por ter um dos menores Índices de Desenvolvimento Humano - $\mathrm{IDH}^{1}$ do Estado (ORGANIZAÇÃO DAS NAÇÕES UNIDAS/PNUD, 2000). Nessa situação encontram-se 704 famílias assentadas pelo processo de reforma agrária e mais 400 famílias acampadas em áreas ocupadas, pouco assistidas pelos serviços de educação e saúde, créditos para produção, acesso a beneficiamento e comercialização de seus produtos.

Em se tratando de assentamentos de reforma agrária, é importante ressaltar aqui que, desde o congresso nacional do Movimento dos Trabalhadores Rurais Sem-Terra (MST) ocorrido em 2000, o Setor de Produção, Cooperação e Meio Ambiente (SPCMA) do Movimento assumiu como matriz tecnológica a agroecologia. Nesse sentido, o MST busca que as atividades produtivas das famílias assentadas estejam voltadas a essa matriz tecnológica. No entanto, muitos assentamentos, principalmente os mais antigos, ainda conservam muito arraigado o padrão tecnológico imposto pela modernização da agricultura como pressuposto para a produção.

Esse é o caso do Assentamento 25 de Maio, objeto de estudo deste trabalho, localizado no município de Santa Terezinha, pertencente à região Norte catarinense, onde 49 das 51 famílias assentadas têm no fumo a sua principal atividade geradora de renda. Em 2007, o município de Santa Terezinha foi o terceiro maior produtor de fumo de Santa Catarina, produzindo 10.494 toneladas de folhas.

Como alternativa à produção de fumo desse assentamento, iniciou-se uma investigação que aponta os limites e as possibilidades da reconversão do fumo à diversificação das unidades produtivas familiares, tendo como base principal a produção de plantas medicinais, aromáticas e condimentares (PMACs). Essa cadeia produtiva está sendo incentivada na região através do projeto "Produção e industrialização de plantas medicinais: resgate cultural e viabilidade técnica, econômica e comercial nas áreas de assentamentos de reforma agrária do Norte de Santa Catarina", aprovado em 2007 pelo edital universal do Conselho Nacional de Desenvolvimento Científico e Tecnológico (CNPq) e viabilizado mediante uma parceria entre a Universidade Federal de Santa Catarina (UFSC), através do Laboratório de Educação do Campo e Estudos da Reforma Agrária (LECERA), Instituto Nacional de Colonização e Reforma Agrária (INCRA) de Santa Catarina e MST.

Considera-se que a compreensão da percepção dos assentados em relação aos riscos emergentes da atividade fumageira é contribuição importante no estabelecimento das condições de uma bem sucedida reconversão produtiva agroecológica. Para tanto, o propósito fundamental deste paper é refletir sobre o cenário atual de um processo de construção da compreensão coletiva dos riscos da atividade fumageira entre todos os envolvidos. Isso requer reconhecer como os agricultores legitimam as práticas atuais e, a partir disso, vislumbrar possíveis caminhos. Parte-se da hipótese que, para a compreensão coletiva dos riscos no contexto particular do Assentamento 25 de Maio, o interesse está mais centrado na qualidade - forma - da transmissão e diálogo do que na quantidade de informação transmitida.

Assim, é necessário inicialmente compreendermos qual é a proposta teórica por trás da abordagem da construção coletiva do risco para, na sequência, analisarmos em deta-

\footnotetext{
${ }^{1}$ É uma medida comparativa que engloba três dimensões: riqueza, educação e esperança média de vida. É uma maneira padronizada de avaliação e medida do bem-estar de uma população. O índice foi desenvolvido em 1990 pelo economista paquistanês Mahbub ul Haq e vem sendo usado desde 1993 pelo Programa das Nações Unidas para o Desenvolvimento no seu relatório anual (ORGANIZAÇÃO DAS NAÇÕES UNIDAS/PNUD, 2000).
} 
lhe o caso da percepção dos riscos associados à atividade fumageira das famílias desse assentamento com vistas à reconversão produtiva do fumo por PMACs.

\section{Percepção de risco: entre a incerteza científica e a incerteza social}

Foi na década de 1970 que, perante as evidências de uma crise ambiental com características globais, começou a ser desenvolvido um profundo debate dentro das ciências sociais sobre a questão ambiental. Assim, a Sociologia Ambiental aparece como um conjunto de propostas para entender as interações socioambientais. Recorda-se, por exemplo, a proposta de mudança radical de paradigma proposta por Dunlap e Catton (1979) caracterizada no NEP (New Ecological Paradigm), ressaltando a influência recíproca entre o ambiente biofísico e o homem.

Os grandes debates na arena da Sociologia Ambiental, segundo Buttel (1996; 2000) são: primeiro, as análises estruturais da relação natureza sociedade, ou seja, os processos sociais com implicações ambientais e, segundo, os estudos mais associados aos valores, à cultura, às atitudes e às intenções dos agentes na gênese e desenvolvimento dos problemas ambientais.

Esses debates se desenvolvem entre vários matizes de dois enfoques: por um lado os Realistas, dentre os quais Dunlap e Catton se situavam, defendendo a existência objetiva dos problemas ambientais, independentemente da forma como os atores sociais os percebem e, por outro lado, os Construtivistas, como F. Buttel, que centraram suas análises nas representações sociais sobre os problemas ambientais, retirando a preponderância da "verdade objetiva" sobre um problema ambiental e dando maior ênfase em como este é definido e quais significados lhe são atribuídos pelos diversos atores sociais.

No entendimento construtivista, o que é socialmente considerado como um problema ambiental não implica somente uma interpretação imparcial de um fenômeno real ou estar definindo ou caracterizando alguns fatos objetivos sobre a natureza e seu comportamento, mas de demandas construídas socialmente. Os problemas ambientais seriam construções sociais nos níveis cognitivo, cultural e político de agentes sociais.

Tendo a questão ambiental como parte da própria definição do processo social, são lançadas propostas de novas teorias sociais, como a "Sociedade do Risco" de Ulrich
Beck (1998). Nela, atribui-se a responsabilidade da definição de riscos ambientais potenciais à ciência. Beck não se identifica com nenhuma posição (realista ou construtivista), mas parece oscilar entre elas, propondo a combinação entre construtivismo e realismo para enfrentar o caráter dual dos riscos. Por um lado, sua imaterialidade ou definição social e, por outro, sua materialidade, que é o efeito concreto produto de uma ação.

Entretanto, Mary Douglas e Aaron Wildavsky (1983) argumentam que a visão de uma sociedade sobre o mundo natural reflete seus valores e sua cultura, impossibilitando o conhecimento "objetivo" da natureza.

Esta tendência enfatiza fortemente o caráter cultural de toda definição de risco, levando à diluição das diferenças entre leigos e peritos junto com uma diferenciação de uma pluralidade de racionalidades dos atores sociais na forma de lidar com os riscos, como é destacado por Guivant (1994; 2005). Nesta visão socioconstrutivista do risco, os indivíduos são organizadores ativos de suas percepções, impondo seus próprios significados aos fenômenos (WILDAVSKY apud GUIVANT, 1998).

Esta forma de percepção "sociocultural" é entendida como um processo mediante o qual as pessoas se conhecem e se avaliam entre si e através do qual se considera a forma como acontecem os fatos de seu grupo social. Assim, pode-se considerar a percepção do risco como um conjunto de fatores ambientais, econômicos, sociais, políticos, culturais e psicológicos que lhe darão forma.

A percepção tem se centrado nos juízos dos integrantes dos grupos sociais quando se solicita às pessoas que avaliem suas atividades, as condições ambientais de onde vivem e os elementos culturais. A percepção do risco nas sociedades está relacionada com a interação de diversos fatores que, de alguma maneira, influenciam, condicionam, determinam ou limitam a forma de valorizar os efeitos que eles ocasionam.

Dentro desta linha construtivista, Hannigam (1995) indica que os riscos não são socialmente processados se não forem cognitivamente construídos por agentes sociais, sob o argumento de que certos problemas ambientais só se tornaram visíveis para o cidadão comum depois de apontados por agentes especializados (ciência ou mídia). Por isso, seria necessário aclarar o processo social (político, cultural) através do qual certas dimensões da vida humana em sociedade são construídas como questões ambientais.

Neste sentido, Guivant (1998; 2005) destaca que, devido à percepção e à gestão dos riscos de acordo com 
princípios inerentes às formas particulares de organização social, deixa de ser possível tratar os riscos de forma neutra, com ferramentas metodológicas quantitativas. É necessária uma compreensão das intersubjetividades que conformam a percepção social dos riscos e, sobre esta base, promover processos de comunicação e construção de alternativas para enfrentá-los.

Da mesma forma, e face ao alto grau de incerteza científica, técnica e social (BECK, 1998) que é imposto a qualquer tentativa de previsão, torna-se necessário, muito mais do que predizer, desenvolver a gestão do risco de uma forma preventiva. A gestão do risco deve, no entanto, ser enquadrada no âmbito de uma abordagem estruturada para sua análise que compreende três elementos: avaliação, gestão e comunicação do risco, o que implica a mobilização ou a recomposição de redes tanto científicas como sociais (CALLON, 1989; GODARD, 1997).

Nesta compreensão da gestão do risco, o trabalho analisa o cenário local fundando as bases para um futuro processo de reconversão produtiva. No diálogo com a comunidade são avaliadas as características dos riscos e as percepções visando à viabilização de uma gestão compartilhada dos riscos. Isso começa com um acertado processo de comunicação dos mesmos, reconhecendo tanto as informações que possuem os técnicos como as decorrentes da experiência prática dos agricultores. A singularidade do assentamento relacionada à participação num movimento social agrega características particulares à percepção dos agricultores, pois eles possuem uma visão mais politizada da atividade. Isso, somado à disposição ao trabalho grupal, pode favorecer processos participativos de comunicação do risco. Entretanto, é necessário mais investigação no sentido de adquirir ferramentas para construção coletiva de medidas de emergência e prevenção dos riscos pelo fumo e ações pedagógicas para dinamizar a informação que já se tem. Isso como parte da transição inerente à reconversão produtiva já citada.

\section{A construção da percepção de risco das famílias do Assentamento 25 de Maio}

Compreende-se que a saúde e o bem-estar das pessoas estão intimamente ligados à saúde dos ecossistemas.
As atividades humanas têm efeitos profundos sobre estes, com implicações complexas e dinâmicas sobre os meios de vida, a saúde humana e o desenvolvimento. Desde a década de 1970, e principalmente a partir da Carta de Ottawa ${ }^{2}$, vem sendo assumida a abordagem ecossistêmica da saúde humana. Este entendimento da saúde tem os seguintes princípios: compreender os problemas em seu contexto e complexidade, mas atuar localmente; envolver todos os atores sociais (população, governantes, gestores, empresários, profissionais e técnicos) na solução dos problemas; usar a ciência e a tecnologia como estratégias de mudanças; trabalhar com o conceito de participação social; contemplar os papéis diferenciados de homens, mulheres, crianças e idosos na construção social da mudança; adotar uma perspectiva inter e transdisciplinar, em que "fragmentos disciplinares" são acionados e postos em cooperação visando à qualidade de vida e ao ambiente saudável (INTERNATIONAL DEVELOPMENT RESEARCH CENTRE, 2009).

Enquadrado nesta concepção e como pano de fundo deste trabalho está o conceito ampliado de saúde para o MST, o qual considera que a saúde humana e ecossistêmica está condicionada ao acesso à "terra, trabalho, moradia, alimentação, educação, saneamento básico, transporte, saúde pública, cultura, meios de comunicação, energia elétrica onde haja justiça, igualdade, participação e organização" (MST, 2000, p. 12).

Unido ao anterior conceito está o pressuposto de que o exercício de construção coletiva da percepção de risco do fumo, além de encaminhar sua gestão, proporciona um ponto de partida favorável à reconversão produtiva a ser concebida em conjunto pelos assentados, técnicos, o Movimento e o projeto já mencionado.

Porém, um problema importante da perspectiva da Sociedade do Risco de Beck (1998) é que está fortemente ancorada na noção de igualdade de riscos. Entretanto, o que encontramos no meio rural evidencia precisamente o contrário, quer dizer, a forte desigualdade existente face aos riscos. Apesar de que pode ser estabelecida uma visão dos riscos globais decorrentes da atividade fumageira, vale a pena reconhecer que não existe uma evidente igualdade de risco. Aliás, é fácil perceber como o risco decorrente da existência da commodity "tabaco" se expressa com diversas intensidades entre todos os envolvidos. Claramente há desigualdade de riscos entre as categorias produtor $\mathrm{e}$

${ }^{2}$ Carta de Ottawa: Primeira Conferência Internacional sobre Promoção da Saúde, realizada em Ottawa, Canadá, em novembro de 1986. 
consumidor e meio rural e meio urbano. É sobre essa base que apontamos as singularidades dos riscos e sua percepção especificamente no Assentamento 25 de Maio.

Das 51 famílias que habitam o assentamento, apenas 44 são regularmente assentadas e sete permanecem em situação irregular perante o INCRA. O número de entrevistados totalizou 18 famílias $-41 \%$ do total de famílias entre as 44 regulares - e foi determinado pelo ponto de saturação ou redundância das respostas (DUARTE, 2002). Das duas únicas famílias que não são fumicultoras, uma delas foi entrevistada e está entre as 18 entrevistas realizadas. Para as entrevistas, utilizou-se a categoria semiestruturada, também chamada de entrevista de profundidade.

As entrevistas objetivaram obter das famílias assentadas informações sobre a situação atual da produção e uso de PMACs - breve levantamento etnoecológico ${ }^{3}$, o processo produtivo do fumo e a percepção dos riscos dessa atividade para as famílias, além de outras informações que possam indicar o potencial das famílias à reconversão da matriz tecnológica e todas as implicações que traz consigo.

Percebeu-se que na produção de tabaco aparecem, por um lado, os riscos decorrentes das próprias características do sistema produtivo (pacote tecnológico) exigido pela empresa fumageira ${ }^{4}$ implementado pelos assentados e, por outro lado, os riscos emergentes da forma de produzir dos agricultores, o que se associa aos fatores cultural e social.

Nesse momento, será discutida a percepção das famílias em relação aos riscos da atividade fumageira que, evidentemente, é parte de um processo sociocultural, carregado com a singularidade do movimento social ao qual pertencem. Além do caráter subjetivo da percepção associado ao fator cultural - imaterial, nos termos de Beck -, soma-se o conhecimento das ameaças e riscos concretos para a saúde, fornecidos através das bases conceituais do MST descritas acima. Essa condição parece preparar melhor os assentados para entender o caráter dual dos riscos no sentido apontado por Beck (1998).

Primeiramente, é importante destacar que todas as famílias percebem riscos, porém em diferentes níveis. Esses níveis podem estar relacionados à formação política (grau de inserção e participação na organização interna do MST); aproximação com entidades que trabalham com saúde e com camponeses; grau de escolaridade e faixa etária das famílias.

O risco econômico é claramente priorizado frente à ideia de que estão expostos a outros riscos graves o suficiente - seja na saúde, seja no ambiente - para motivar atitudes preventivas, como também a mudança de atividade. Todas as famílias entrevistadas deixariam de produzir o fumo; contudo, o retorno econômico que a atividade gera é o fator que não permite a saída. Essa situação reflete o posicionamento de Wildavsky, quando este se refere aos indivíduos como organizadores ativos de suas percepções.

Outra condição apontada pelas famílias, que está associada e dá mais credibilidade ao risco econômico, é a falta de estrutura e opções ao desenvolvimento de outras atividades. Elas relatam que quando foram assentadas plantaram hortaliças, feijão, milho para comercializar, porém, não encontraram na região onde vender. Chegaram à condição de alimentar os animais e/ou deixar na roça, porque não havia e ainda não há estrutura de escoamento e comercialização de outros produtos na região, a não ser o fumo.

Os autores Guivant (1994) e Lima et al. (2002), em suas pesquisas, reportam que, em casos nos quais as comunidades também optam por responder aos riscos econômicos acima dos demais riscos, os agricultores decidem pela aplicação de maior dosagem de insumos, por exemplo, garantindo maior produção. Contudo, no Assentamento 25 de Maio isso não é verificado e a principal resposta ao risco econômico se dá através do aumento da área plantada.

Pôde-se perceber que para os entrevistados estão muito mais claros os riscos "agudos" ou de curto prazo da atividade fumageira que os riscos "crônicos" ou de médio e longo prazos. Ou seja, é muito mais palpável a ideia da intoxicação aguda por agrotóxicos que um provável câncer causado pelo contato frequente com essas substâncias. Segundo os entrevistados, esses problemas só aparecem em outras famílias ou outros locais.

Essas situações propiciam um mecanismo de adaptação aos demais riscos (GUIVANT, 1994), gerando um otimismo irreal ou tranquilidade que se baseiam na informação disponível e em um raciocínio que induz a ideia de que

\footnotetext{
${ }^{3}$ Esse levantamento etnoecológico consistiu em coletar dados sobre quais são as PMACs conhecidas pelas famílias assentadas, para que são utilizadas (enfermidades), como são utilizadas (chás, emplastros, infusões), quais partes das plantas são utilizadas (raiz, caule, folhas), quais são cultivadas e quais são coletadas, entre outros. ${ }^{4}$ Empresa fumageira é a empresa que compra o fumo dos fumicultores para repassar às indústrias de cigarros, por meio de um contrato de integração. As fumageiras instaladas no Brasil foram as pioneiras nesse tipo de contrato, no qual a empresa subsidia os insumos necessários a determinada produção (no caso, fumo), garantindo a compra do produto, e o produtor entra com sua terra e força de trabalho. No momento da venda do produto, é descontado o valor do financiamento dos insumos disponibilizados.
} 
eles não são ameaças reais, muito embora afetem pessoas conhecidas. Tudo isso influencia a resposta ao risco, mas, principalmente, permite que os agricultores continuem se arriscando a produzir fumo, circunstância que contribui na resposta à controvérsia mais evidente nas entrevistas: todas as famílias se consideram empregados das fumageiras, até mesmo trabalhadores escravos - pelo volume de trabalho em alguns períodos da produção -, além de adoentados, intoxicados e endividados, porém nenhum deles deixa a atividade.

A percepção dos riscos sobre a saúde pelas famílias entrevistadas foi dividida em três situações para melhor detalhamento: a) relacionados à intoxicação aguda por agrotóxicos; b) problemas físicos ocasionados pelo trabalho com o fumo; e c) outras doenças relacionadas à cultura do fumo.

De forma geral, as famílias evitam ir ao médico quando doentes, primeiramente porque o serviço só é disponível na área urbana do município, distante $12 \mathrm{~km}$ em estrada de chão. Para enfermidades mais normais e corriqueiras - como resfriado, gripe e vermes - são feitos tratamentos à base de PMACs e os recursos do SUS só são acessados quando não há alternativa em casa. Esse comportamento também está associado ao fato de que na agricultura familiar a força de trabalho é superexplorada e, portanto, indispensável. Nesse sentido, ficar doente e sem trabalhar é uma situação considerada entre eles como o último recurso.

As intervenções sobre a intoxicação por agrotóxicos estão presentes em todas as entrevistas. Segundo os relatos, todas as famílias já tiveram um ou mais membros da família intoxicados por agrotóxicos. A situação é tão grave e ao mesmo tempo tão rotineira que chega a ser expresso que algumas famílias compram sulfato de atropina ${ }^{5}$ antecipadamente, preparando-se para prováveis intoxicações. Esse fenômeno pode ser considerado um exemplo de mecanismo de adaptação a riscos.

As famílias também compreendem que o uso de Equipamento de Proteção Individual (EPI) poderia diminuir a frequência das intoxicações; entretanto, o equipamento não é adequado ao uso, sendo muito pesado, incômodo e quente. Essa ação menos preocupada dos agricultores frente à aplicação de agrotóxicos na cultura do fumo permite duas interpretações relacionadas à assistência técnica fornecida pelas empresas integradoras: ou as empresas, através de seus técnicos, não prestam a assistência técnica a que se propõem, estipulada em cláusulas no contrato de integração, deixando livre para que os agricultores executem como queiram, ou os técnicos fazem "vistas grossas" ao mau uso do EPI, o que ao conselho de classe - no caso o Conselho Regional de Engenharia, Arquitetura e Agronomia (CREA) - é passível de penalidades.

Entretanto, se a análise partir dos mecanismos de adaptação aos riscos, essa atitude dos agricultores frente à aplicação de agrotóxicos pode ser percebida como uma classificação de critérios que servirão como parâmetros mínimos para o bom desenvolvimento da produção de fumo sem causar modificações na forma de produzir - o que poderia acarretar riscos econômicos.

Essa atitude de categorização dos riscos pode ser considerada como uma possibilidade de "fuga" ou alívio que os agricultores têm ante todas as pressões associadas ao cultivo do fumo.

Outra situação, muito frequente no assentamento, que traz riscos à saúde para as pessoas envolvidas no processo produtivo do fumo está ligada aos problemas físicos decorrentes da atividade fumageira. Verificou-se que muitas famílias têm pessoas com problemas de hérnia, coluna e tendinites resultantes do pesado trabalho com o fumo. A capina requer condições físicas que cumulativamente culminam em problemas na coluna e articulações.

Além da capina, outra atividade que causa danos físicos às pessoas que produzem fumo é a colheita. A colheita inicia-se das folhas mais baixas - "baixeiro" - para as mais altas. Para tanto, as posições são agachado ou curvado, o que traz sérios danos à coluna. E, para finalizar, o maior esforço no sistema produtivo do fumo está na secagem. A estufa possui uma estrutura interna chamada de estaleiro, onde se penduram os grampos ou varas com as folhas para secar. Cada estaleiro seria um andar de folhas e a estufa começa a ser carregada de cima para baixo. Portanto, para colocar as primeiras folhas para secar é necessário levantar as varas ou grampos e alcançá-las às pessoas que irão recebê-las e pendurá-las nos primeiros estaleiros. Essa ação de pegar do chão as folhas pesadas e erguê-las é extremamente desgastante. Em uma família do assentamento, uma das pessoas está com sérios problemas de coluna por executar essa atividade. Essa pessoa está prestes a fazer uma cirurgia, com risco de amputação e já perdeu os sentidos em dois dedos do pé.

\footnotetext{
${ }^{5}$ Sulfato de atropina é o antídoto mais utilizado para intoxicações agudas provocadas por uma série de agrotóxicos, muitos deles utilizados na produção do fumo. Suas contraindicações são inúmeras e seu uso é restrito.
} 
Mais uma condição apresentada pelos agricultores é o número elevado de deficientes físicos que, segundo eles, existe no município de Santa Terezinha. Essa situação não pôde ser comprovada, pois não foi possível conversar com as autoridades de saúde municipais. Todavia, a condição foi lembrada e apresentada pelos agricultores no momento da entrevista e, portanto, deve ser considerada.

Mais enfermidades relacionadas ao fumo foram levantadas, no entanto, por um menor número de famílias. Algumas delas notificaram a presença da Doença do Tabaco Verde (DTV) ${ }^{6}$, enfermidade comum, porém somente há alguns anos essa doença passou a ter destaque em estudos e pesquisas, situação que pode estar relacionada a dois fatores: à similaridade entre os sintomas de ambas as intoxicações (por agrotóxico e DTV), o que levou ao mesmo tratamento, ou ao sistema produtivo do fumo altamente tecnificado nos países desenvolvidos, que utiliza pouca força de trabalho humana. Dessa forma, poucos ou raros casos de DTV foram identificados, o que não despertou grande interesse da comunidade científica desses países até então.

$\mathrm{O}$ pouco destaque dado à DTV resulta no pouco conhecimento dos profissionais da saúde que atuam nas regiões fumageiras. Apesar de algumas similaridades nos sintomas, possuem tratamentos diferentes e tratar DTV como intoxicação por agrotóxicos pode trazer mais problemas. Isso porque o sulfato de atropina mascara alguns sintomas, trazendo a sensação de melhora, tardando o diagnóstico correto.

O fator percepção dos riscos ao consumidor, apesar de também tratar de riscos à saúde, possui características diferentes e poucas famílias o percebem. O mais interessante é que os agricultores não percebem o risco à saúde do consumidor pela ingestão da nicotina, somente pela ingestão dos agrotóxicos. Isso pôde ser identificado em todos os relatos que continham essa percepção. São poucos os fumantes entre as famílias entrevistadas, mas ainda há. Somente um dos fumantes opinou sobre o risco do consumo e declarou que produz seu próprio fumo, já que considera $o$ da fumageira envenenado.

A percepção dos riscos ambientais apontados pelas famílias também está vinculada aos agrotóxicos. Os entrevistados e entrevistadas referem-se à utilização do herbicida Clomazone, marca comercial Gamit, classificado como altamente tóxico e altamente perigoso ao meio am- biente. Esse herbicida inibe a floração de muitas frutíferas, principalmente as chamadas "de clima temperado", mais frequentes no assentamento. Muitos narraram que não colherão frutas como pera, tangerina e pêssego neste ano.

Uma das famílias entrevistadas produz mel, mas suas caixas estão muito bem protegidas entre um arvoredo contíguo à área de reserva legal do seu lote. A família conta que chegou a ficar sem mel, porque as abelhas não estavam produzindo. As caixas estavam colonizadas, era época de produção, mas não havia mel suficiente para colheita, atribuindo o fato ao uso de agrotóxicos no assentamento.

Apenas uma família enfatizou o efeito residual dos agrotóxicos e nicotina no solo, atribuindo o insucesso dos plantios sucessivos ao fumo. Merece destaque o não reconhecimento dos riscos ambientais relacionados à água, já que esse assentamento conta com muitas nascentes e contribuintes do Rio da Prata, importante rio da Bacia Hidrográfica do Rio Itajaí.

O risco de contaminação das águas é alto nesse assentamento. Além da grande quantidade de nascentes e cursos d'água, que facilmente podem ser atingidos por aplicação dos agrotóxicos, esse risco é agravado pela susceptibilidade à erosão presente nos solos constituintes do 25 de Maio, que se encontra entre moderada e forte. O preparo intensificado do solo para o plantio de fumo o deixa descoberto, propiciando ainda mais a erosão pluviométrica e eólica, levando nas partículas de solo desagregadas partículas de agrotóxicos que se depositarão no fundo dos mananciais e cursos d'água.

Essa situação de fraca percepção sobre a contaminação ambiental gerada pelo sistema produtivo do fumo exemplifica a discussão já feita nesse tópico relacionada aos riscos agudos e/ou imediatos - que são mais ponderados pelos agricultores que os riscos que só trarão prejuízos ao longo do tempo -, uma vez que o assoreamento dos cursos d'água e os resultados negativos da erosão só são percebidos em uma escala de tempo maior.

A percepção de risco nas relações de trabalho é claramente identificada em todas as entrevistas. $\mathrm{O}$ contrato de integração entre as empresas fumageiras e os agricultores os mantém atrelados e dependentes da produção de fumo e das imposições produtivas e econômicas que as empresas apresentam. O pacote tecnológico exigido por essas empresas determina a produtividade a ser alcançada, a infraestrutura

\footnotetext{
${ }^{6}$ Doença do Tabaco Verde (DTV): intoxicação aguda causada pela absorção de nicotina pelas folhas do tabaco através da pele.
} 
necessária, a quantidade e os insumos utilizados, os preços pagos por esses insumos ${ }^{7}$, além do valor a ser recebido pelo produto entregue ${ }^{8}$. Como se trata de uma relação de contrato e endividamento, a cada mês ou safra há novos insumos e/ou novas tecnologias a serem implantadas e, portanto, dificilmente há um agricultor de fumo que esteja com as contas em dia com a fumageira.

Apesar da renda com o fumo ser alta se comparada a outras commodities agrícolas, quando for dividida pelos meses que abrangem o período entre o preparo da terra até a entrega do produto e for contabilizado o trabalho gasto por todas as pessoas envolvidas em todo o processo produtivo, esse valor acaba sendo muito baixo. Entretanto, para o agricultor familiar é aparentemente rentável, uma vez que este superexplora a sua força de trabalho.

Uma estratégia das transnacionais é reduzir ao mínimo a relevância dos riscos da produção fumageira, diluindo a capacidade dos agricultores de percebê-los, mantendo-os no modelo produtivo de seu interesse. Isso é refletido em algumas narrativas dos entrevistados, quando afirmam que se fizerem exatamente de acordo com as instruções das fumageiras não terão com o que se preocupar e a produção será boa. As fumageiras, na visão de Hannigan, descrita no item 2, são um dos agentes especializados que deveriam aclarar os riscos inerentes da atividade; todavia, não o fazem, em benefício próprio.

Essa análise das percepções de risco na perspectiva das famílias assentadas se consolida como o ponto de partida para uma futura reconversão produtiva, na medida em que as próprias famílias fazem uma reflexão e uma leitura mais clara e crítica de todo o processo produtivo e do que as mantém na atividade fumageira.

\section{Em busca do processo de reconversão produtiva no contexto do Assentamento da Reforma Agrária 25 de Maio}

É fato que a falta de apoio da estrutura pública no momento da consolidação do assentamento, encontrada até os dias de hoje, promoveu a entrada do fumo como única alternativa de renda para as famílias assentadas no 25 de Maio e, praticamente, para a região.

Entretanto, os seguintes fatores observados no assentamento podem, junto com o exercício realizado no tópico acima, contribuir para a reconversão produtiva que se busca. Inicialmente, ressalta-se um conjunto de características importantes da cultura camponesa que os assentados imprimem em suas formas de viver, produzir e se relacionar com o meio.

O desenho que as famílias fazem de seus lotes ou unidades produtivas familiares é inerentemente diversificado. Apesar da intensa presença do fumo, as famílias garantem sua produção para autoconsumo, uma preocupação muito visível entre eles, demonstrada pela variedade de alimentos disponíveis para o uso familiar, como hortaliças, frutas, PMACs, animais, milho, feijão, batata e mandioca. Isso foi expresso por muitas famílias, que se orgulham em dizer que vão ao mercado apenas para comprar sal e arroz.

Também estão garantidas, entre as famílias, atividades paralelas ao fumo geradoras de renda secundária, como: produção de leite e derivados, fruticultura, milho, feijão, hortaliças e artesanato feito pelas mulheres. Todavia, essas atividades são muito incipientes, na medida em que as famílias estão conscientes de que não há onde escoar grandes produções.

Há, no assentamento, uma cozinha comunitária em processo de implantação. Essa cozinha será uma importante contribuição à diminuição da referência econômica do fumo. Com ela, as famílias pretendem desenvolver o beneficiamento de frutas, hortaliças e PMACs.

Especificamente às PMACs, as famílias citaram 76 plantas que são utilizadas frequentemente, seja para chás, temperos, infusões, emplastros, repelentes, entre outros, fato que demonstra os seus conhecimentos tradicionais. É interessante notar que muitas famílias colhem e utilizam PMACs da vegetação nativa; entretanto, nenhuma família é natural da região, pois vieram do oeste do Estado. Isso revela uma fusão entre o conhecimento tradicional trazido e o conhecimento tradicional local que foi adquirido, construindo um conhecimento novo e próprio dessas famílias.

\footnotetext{
${ }^{7} \mathrm{O}$ integrado (agricultor) adquire os insumos necessários referentes à área que irá plantar, fornecidos pela integradora (empresa fumageira) no momento do contrato de integração, mas só vai pagá-los na entrega do produto. O valor cobrado pelos insumos é preestabelecido; entretanto, pode aumentar caso a produtividade esperada e calculada no momento do contrato não seja alcançada.

${ }^{8}$ Há uma tabela oficial de classificação do fumo, contendo 41 possibilidades, e cada uma delas paga um valor diferente à arroba de fumo (unidade de massa igual a $15 \mathrm{~kg}$ ). No momento do enfardamento do fumo para entrega na empresa, o integrado faz uma pré-classificação do seu produto baseado nessa tabela. Entretanto, essa classificação não é a final, já que no momento de entrega a empresa faz uma nova classificação dos fardos na presença do produtor e, por muitas vezes, a avaliação da integradora é inferior à avaliação do produtor, pagando menos por um produto de maior qualidade.
} 
O fato de estarem organizados em torno de um movimento faz com que suas demandas e necessidades fiquem mais visíveis, o que favorece as possibilidades de apoio e atenção, como o acesso a recursos através de editais e projetos, por exemplo. Já a formação política proporcionada pelo MST facilita a compreensão das próprias famílias enquanto sujeitos de transformação da sua própria realidade, o que leva a uma visão mais crítica de suas próprias atitudes.

Assim sendo, o exercício de propiciar um cenário reflexivo em torno da percepção dos riscos decorrentes da atividade fumageira, somado à existência - ainda embrionária - de articulação entre a linguagem leiga e técnica no interior do assentamento, já começa a mostrar seus efeitos sobre o caminho da reconversão produtiva. Contudo, sua contribuição como um elemento desencadeador de transformação vai além do aspecto produtivo, visando à autonomia. Não se espera que o exercício de análise da percepção dos riscos pare na atividade fumageira e é importante que essa ferramenta seja utilizada para outras atividades e dimensões da vida humana também.

A análise da percepção dos riscos das famílias do Assentamento 25 de Maio permitiu verificar que o entendimento delas face aos riscos da saúde já está bem avançado; porém, deve-se investir no maior desenvolvimento da percepção aos riscos ambientais. Não se trata de afirmar que as famílias não os reconhecem, mas ainda o fazem de forma superficial e pouco vinculada à diferença entre $o$ sistema produtivo do fumo e o sistema produtivo que elas adotaram em relação às demais atividades.

Nas entrevistas, os agricultores mostram um claro posicionamento frente ao fumo, apontando nele a causa de sua situação de dependência da empresa fumageira e da deterioração de suas condições de trabalho e de saúde. Em consequência, declaram-se interessados e dispostos a modificar sua atividade produtiva, porém, com a garantia de um processo fortemente estruturado que vá criando as condições de estabilidade econômica - que na percepção deles são razoavelmente asseguradas pelo fumo.

$\mathrm{Na}$ singularidade do assentamento, a referida dicotomia entre o conhecimento leigo e o conhecimento perito (GUIVANT, 1994; 2005; BUTTEL, 1996; 2000; BECK, 1998; DUNLAP; CATTON, 1979; DUNLAP, 2002) aparece difusa devido ao fato de que recebem assistência técnica do programa $\mathrm{ATES}^{9}$, que no Estado é fornecida por uma cooperativa de técnicos que trabalham especificamente para a reforma agrária. Isso garante, a princípio, que esta seja oferecida de forma criteriosa em termos técnicos e políticos. Reconhecendo, é claro, que o Movimento vem reformulando e continua a reformular suas estratégias de ação, introduzindo novas variáveis como a agroecologia e a questão ambiental. Dado que os técnicos da ATES seguem orientações do INCRA e do MST, no caso específico do Assentamento 25 de Maio eles não interferem na atividade fumageira, já que não se trata de uma cultura alimentícia e as empresas fumageiras fornecem sua própria assistência.

Para o MST, além desses fatores, a atividade também está carregada de contradições políticas, haja vista que está vinculada a um complexo agroindustrial transnacional antagônico ao modelo proposto por eles. Isso gera nas famílias assentadas um estado contraditório, na medida em que percebem os seus efeitos negativos mais do que outros agricultores que estão na atividade fumageira. Todavia, se mantêm na atividade pela condição econômica, como já foi discutido.

Portanto, é preciso um contínuo fortalecimento da análise e gestão do risco através do aprimoramento dos processos pedagógicos, de mobilização da comunidade e de comunicação dos riscos por parte das lideranças que estão mais engajadas na linguagem técnica e nas posturas políticas do movimento.

Ressalta-se que a reconversão produtiva agroecológica é uma intenção para todas as áreas de reforma agrária pertencentes ao MST que ainda não adotaram a agroecologia como matriz tecnológica e a produção de alimentos como fonte de renda. No entanto, essa reconversão encontra-se em diferentes níveis no conjunto desses assentamentos, resultado do grau de envolvimento das famílias com as atividades produtivas convencionais. No caso do Assentamento $25 \mathrm{de}$ Maio, a dita reconversão ainda está em construção.

À parte da intenção das famílias na reconversão a outra atividade, incentivos advindos da esfera pública têm que estar disponíveis para que, realmente, haja alternativas viáveis ao fumo na região. Isso implica em parcerias com outros órgãos públicos (Conab, por exemplo); facilidade à instalação de agroindústrias de caráter familiar, que beneficiem alimentos como leite, hortaliças, PMACs e

\footnotetext{
${ }^{9}$ ATES: Assistência Técnica Social e Ambiental. Programa do INCRA em nível nacional que garante assistência técnica diferenciada às famílias beneficiárias da reforma agrária. Esta diferenciação está pautada no desenvolvimento rural voltado à agricultura familiar, dentro da matriz agroecológica, visando à obtenção de renda a partir da produção de alimentos.
} 
frutas; estruturação de armazéns e depósitos de alimentos; efetivação da política de merenda escolar com alimentos da agricultura familiar; melhora na estrutura viária da região; créditos mais acessíveis para a produção de alimentos; manutenção da assistência técnica diferenciada a assentados e à agricultura familiar, entre outros.

A partir do exercício de análise discutido nesse documento, nota-se que caminhos à compreensão dos riscos da cadeia produtiva do fumo estão em processo de construção

\section{Referências}

ASSOCIAÇÃO DOS FUMICULTORES DO BRASIL. Perfil do fumicultor sul-brasileiro - distribuição fundiária, safra 07/08. Santa Cruz do Sul: AFUBRA, 2009. Disponível em: $<$ http://www.afubra.com.br/principal $>$. Acesso em: janeiro de 2009.

BACKES, B. I. Gestão da responsabilidade social em indústrias beneficiadoras de tabaco. Tese (Doutorado em Engenharia de Produção) - Universidade Federal de Santa Catarina. Florianópolis, 2008.

BANCO MUNDIAL. Cubing the Epidemic: Governments and the economics of tobacco control. Washington/DC: World Bank, 1999.

BECK, U. La sociedad del riesgo: Hacia una nueva modernidad. Barcelona: Ediciones Paidós Ibérica S/A., 1998.

BOEIRA. "Atrás da Cortina de Fumaça" - Tabaco, tabagismo e Meio Ambiente: estratégias da indústria e dilemas da crítica. Tese (Doutorado Interdisciplinar em Ciências Humanas) Universidade Federal de Santa Catarina. Florianópolis, 2000.

BUTTEL, F. Environmental and resource sociology: Theoretical issues and opportunities for synthesis. Rural Sociology, v. 61, n. 1, 1996.

. Sociologia ambiental, qualidade ambiental e qualidade de vida: algumas observações teóricas. In: HERCULANO, S. et al. (Orgs.). Qualidade de vida e riscos ambientais. Niterói: EdUFF, 2000.

CALLON, M. La Science et ses Reseaux: Genese et Circulation des Faits Scientifiques. Paris: E. La Decouverte/Conseil de l'Europe/Unesco, 1989.

CARVALHO, C. B. Relação socioeconômica dos fumicultores-fumageiras da região de Sombrio, SC e uma proposta de pelas famílias assentadas. Há um reconhecimento crítico voltado às relações de trabalho entre elas e as fumageiras, ao uso abusivo de agrotóxicos e aos inúmeros problemas de saúde gerados.

Entretanto, enquanto o poder público não tomar medidas necessárias para apoiar possíveis reconversões, a prioridade dos agricultores aos riscos econômicos da atividade fumageira se manterá preponderante.

transição agroecológica. Dissertação (Mestrado em Agroecossistemas) - Universidade Federal de Santa Catarina. Florianópolis, 2006.

CAVALCANTI, T.; PINTO, M. Considerações sobre o tabaco e pobreza no Brasil: consumo e produção de tabaco. Brasília: Ministério da Saúde - Instituto Nacional de Câncer. 2006. Disponível em: $<\mathrm{http} /$ www.inca.gov.br/tabagismo/publicacoes/ tabaco_pobreza.pdf $>$. Acesso em: fevereiro de 2009.

DOUGLAS, M.; WILDAVSKY, A. Risk and culture. Berkley: University of California Press, 1983.

DUARTE, R. Pesquisa qualitativa: reflexões sobre o trabalho de campo. Cadernos de Pesquisa, n. 115, p. 139-154, 2002.

DUNLAP, R. E. Paradigms, theories, and environment sociology. In: DUNLAP, R. E. et al. (Eds.). Sociological Theory and the environment. Classical foundations, contemporary insights. Oxford: Rowman \& Littlefield Publishers, 2002.

; CATTON, W. Environmental sociology. Annual Revue of Sociology, v. 5, p. 243-273, 1979.

FAO. Cuestiones relacionadas con la Economía Mundial del Tabaco. Genebra: 2003. Disponível em: <ftp://ftp.fao.org/ docrep/fao/007/y4997s/y4997s01.pdf $>$. Acesso em: novembro de 2008.

GODARD, O. L'ambivalence de la precaution et la transformation des rapports entre science et decisions. In: GODARD, O. (Dir.). Le principe de precaution dans la conduite des affaires humaines. Paris: INRA, 1997.

GUIVANT. J. Percepção dos olericultores da Grande Florianópolis (SC) sobre os riscos decorrentes do uso de agrotóxicos. Revista Brasileira de Saúde Ocupacional, v. 82, n. 22, p. 47-57, 1994. 
Apresentação do dossiê Mapeando os Caminhos da Sociologia Ambiental. Florianópolis: Política e Sociedade, n. 7, 2005.

. A trajetória das análises de risco: da periferia ao centro da teoria social. ANPOCS, n. 46, p. 3-38, 1998. Disponível em: $<$ http://www.nisra.ufsc.br/pdf/ trajetoriasdasanalisesderisco. pdf $>$. Acesso em: fevereiro de 2009.

HANNIGAN, J. Sociologia Ambiental: a formação de uma perspectiva social. Lisboa: Instituto Piaget, 1995.

INSTITUTO BRASILEIRO DE GEOGRAFIA E ESTATÍSTICA - IBGE. Levantamento Sistemático da Produção Agrícola - 1999-2009. Brasília: Ministério do Planejamento, Orçamento e Gestão, 2009. Disponível em: <http://www.ibge. gov.br/home/estatistica/indicadores/agropecuaria/lspa/default. shtm>. Acesso em: janeiro de 2009.

INTERNATIONAL DEVELOPMENT RESEARCH CENTRE. Conceito de Ecohealth. Disponível em $<$ http://www. idrc.org.sg/en/ev-3314-201-1-DO_TOPIC.html >. Acesso em: fevereiro de 2009.
LIMA, J. S.; MOREIRA, J. C.; ARAÚJO, A. J.; SOARES, M. O.; AMARAL, A. M.; KUBOTA, A.; MARKOWITZ, S. Riscos coletivos e impacto do uso de agrotóxicos sobre a saúde humana e ambiental: um estudo piloto de saúde ocupacional. Desenvolvimento e Meio Ambiente, n. 5, p. 73-87, 2002.

MINISTÉRIO DA SAÚDE. Tabagismo: orientação e prevenção. Brasília: Ministério da Saúde, 2009. Disponível em: $<$ http://portal.saude.gov.br/portal/saude/visualizar_texto. cfm?idtxt=29479>. Acesso em: fevereiro de 2009.

MOVIMENTO DOS TRABALHADORES RURAIS SEM-TERRA. Cartilha Construindo. Brasília: MST, p. 12, 2000.

ORGANIZAÇÃO DAS NAÇÕES UNIDAS/PNUD. Atlas do Desenvolvimento Humano/Programa das Nações Unidas para o Desenvolvimento. Brasília: ONU, 2000. Disponível em: $<$ http://www.pnud.org.br/atlas/>. Acesso em: janeiro de 2009.

ORGANIZAÇÃO MUNDIAL DA SAUDE - OMS. Relatório da OMS sobre a epidemia global de tabagismo. Genebra: Pacote MPOWER, 2008.

Recebido em junho de 2009.

Aceito em setembro de 2010. Publicado em dezembro de 2010. 